\title{
Lumbar canal stenosis: analyzing the role of stabilization and the futility of decompression as treatment
}

\author{
Atul Goel, MCh, ${ }^{1,2}$ Shashi Ranjan, MCh, ${ }^{1}$ Abhidha Shah, MCh, ${ }^{1}$ Abhinandan Patil, MCh, ${ }^{1}$ and \\ Ravikiran Vutha, $\mathrm{MCh}^{1}$ \\ 1Department of Neurosurgery, K.E.M. Hospital and Seth G.S. Medical College, Parel, Mumbai; and 'Lilavati Hospital and \\ Research Centre, Bandra, Mumbai, India
}

\begin{abstract}
OBJECTIVE The authors report their current experience with their previously published novel form of treatment in 70 cases of lumbar canal stenosis. The treatment consisted of only fixation of the spinal segments by the transarticular screw fixation technique. No bone, ligament, osteophyte, or disc resection was done for spinal canal and neural foraminal decompression. The proposed treatment is based on the concept that vertical instability that results in telescoping of the facets on physical activity forms the nodal point of pathogenesis of lumbar canal stenosis.
\end{abstract}

METHODS During the period June 2014 to May 2018, 70 patients presenting with the classically described symptoms of lumbar canal stenosis were treated surgically by only fixation of involved spinal segments. Apart from clinical and radiological guides, instability was diagnosed on the basis of physical observation of the status of articulation by direct manipulation of bones of the region. The operation involved transarticular insertion of 2 or 3 screws for each articulation. The Oswestry Disability Index and visual analog scale were used to assess the patients before and after surgery and at follow-up. Additionally, a personalized patient satisfaction score was used to assess the outcome of surgery.

RESULTS Clinical symptomatic recovery was observed in all patients in the immediate postoperative period. During the average follow-up period, $100 \%$ of patients had varying degrees of symptomatic relief. The patient satisfaction score suggested that all patients were very satisfied with the surgical procedure. The transarticular fixation technique provided strong spinal segment fixation and a reliable ground for bone arthrodesis. No patient needed any additional modality of treatment or reoperation for recurrence of symptoms.

CONCLUSIONS Spinal instability is the nodal point of pathogenesis of spinal degeneration-related lumbar canal stenosis. Only fixation of the involved spinal segments is necessary-decompression by bone or soft-tissue resection is not necessary.

https://thejns.org/doi/abs/10.3171/2019.2.FOCUS18726

KEYWORDS lumbar canal stenosis; spinal instability; spinal spondylosis; claudication pain

$\mathrm{L}$ UMBAR spinal degeneration that leads to lumbar canal stenosis is a disabling clinical condition. Decompression for lumbar canal stenosis is widely used and accepted and is considered to be a gold standard treatment. Although minimally invasive techniques are currently becoming popular, the basic concept that involves decompression of the neural structures has remained the basis of surgical treatment. The treatment protocol has been based on the traditionally agreed-upon and more than a century old concept that disc degeneration and disc space reduction is the core pathogenetic issue for the ultimate development of spinal canal stenosis. Osteophyte formation and ligamentum flavum buckling lead to compromise of the spinal canal and compression of the traversing nerve roots of the cauda equina.

In 2010, we proposed an alternative concept of pathogenesis of spinal degeneration and related the sequence of events primarily to vertical spinal instability and telescoping of the facets. ${ }^{6,7}$ Standing human posture and its lifelong strain on the muscles, as well as misuse, abuse, or injury 
TABLE 1. Radiological features in 70 cases of lumbar canal stenosis

\begin{tabular}{cc}
\hline \multicolumn{1}{c}{ Feature } & No. of Patients \\
\hline Radiological level involved & \\
\hline L1-2 & 8 \\
\hline L2-3 & 24 \\
\hline L4-5 & 55 \\
\hline L5-S1 & 51 \\
\hline No. of levels fixed & 3 \\
\hline 1 & 32 \\
\hline 2 & 28 \\
\hline 3 & 5 \\
\hline 4 & 2 \\
\hline 5 &
\end{tabular}

of the muscles that are responsible for spinal posture, initiate a cascade of events that ultimately lead to spinal instability. It was observed that spinal instability was impossible or difficult to recognize by radiological imaging, but the consequences are starkly evident in the form of distortion and compression of traversing nerves at single or multiple spinal segments by the phenomenon of lumbar canal stenosis. On the basis of the concept that spinal instability is the core issue, we performed only stabilization of spinal segments without resorting to any kind of bone, soft-tissue, disc, or osteophyte resection for single- or multilevel spinal degeneration for both cervical and lumbar spines. ${ }^{8,10,11,13-15}$

In this presentation we analyze the surgical results in 70 cases diagnosed with lumbar canal stenosis that were treated by fixation only. No decompression of any kind was done.

\section{Methods}

During the period June 2014 to May 2018, 70 cases diagnosed with lumbar canal stenosis were surgically treated at our institutions. This is a retrospective analysis of these 70 consecutively treated cases. Minimum follow-up is 6 months. All patients provided written informed consent before surgery, and all clinical tests and surgical procedures were conducted according to the principles of the Declaration of Helsinki. Cases analyzed in the previous report are not included in this study. 6,7 There were 53 male and 17 female patients. The ages of the patients ranged from 40 to 84 years (average 57 years). All patients had classically described symptoms that are attributed to lumbar canal stenosis, which include claudication pain in the low back and radiation along the posterior aspect of the legs (70), weakness of muscle groups (10), and paresthesia in the distribution of one or more nerve roots (60). Radiological observations are summarized in Table 1. The Oswestry Disability Index (ODI $)^{4}$ and visual analog scale (VAS) were used to grade the symptoms (Table 2). The patients had progressive symptoms and were experiencing failure of nonsurgical or conservative forms of treatment. All patients were investigated both before and after surgery with dynamic (flexion and extension views) plain radiographs, CT scans, and MRI.
TABLE 2. Preoperative and postoperative VAS and ODI scores

\begin{tabular}{|c|c|c|c|}
\hline Scoring System & Preop & $\begin{array}{l}\text { Immediately } \\
\text { Postop }\end{array}$ & $\begin{array}{l}6 \text { Mos } \\
\text { Postop }\end{array}$ \\
\hline \multicolumn{4}{|l|}{ VAS } \\
\hline Back pain & $7.5(4-9)$ & $2.9(0-4)$ & $0.7(0-1)$ \\
\hline \multicolumn{4}{|l|}{ ODI } \\
\hline 0-20\%: minimal disability & 0 & & 59 \\
\hline 21-40\%: moderate disability & 5 & & 11 \\
\hline 41-60\%: severe disability & 51 & & 0 \\
\hline 61-80\%: crippled & 14 & & 0 \\
\hline 81-100\%: bedridden & 0 & & 0 \\
\hline
\end{tabular}

Patients in whom there was radiographic evidence that suggested spinal instability or any degree of spondylolisthesis were excluded.

\section{Surgical Technique}

All patients underwent operation in a prone surgical position that flattened the lumbar lordosis. Standard described precautions and care were adopted. A midline skin incision was made, and by using subperiosteal dissection the facetal articulation was exposed widely on both sides. The spinal level was confirmed by using intraoperative fluoroscopy. All patients underwent transarticular facetal fixation with the technique described by Roy-Camille and Saillant in 1972. ${ }^{21}$ Double insurance, or 2 screws placed in a transarticular fashion, a modification of Roy-Camille's technique that was described by us earlier, was used in all patients. ${ }^{13}$ In 8 patients, 3 screws (triple insurance) were used in a transarticular fashion in at least one of the facetal articulations. The self-tapping monoaxial screws were approximately $18 \mathrm{~mm}$ long and $2.6 \mathrm{~mm}$ in diameter.

Although the clinical symptoms and radiological information were suggestive, direct physical observation and manual manipulation of the facets finally determined the levels of spinal fixation that were carried out. Observation of the open articular cavity, osteophytes in the vicinity of facets, and excessive or abnormal mobility of the facets on manipulation were the indicators that suggested the level of spinal fixation that was indicated and performed. No bone or soft-tissue removal to affect decompression of the dural tube or the traversing neural structures was carried out. Spinous process was cut sharply at the base, and the bone obtained was shredded and used as a graft material. Following screw implantation, all interspinal ligaments were widely resected, and bone of the lamina and the screw-adjoining surface of the facets were decorticated to make the environment suitable as the host bone for graft. The patients were mobilized as soon as possible, but were advised to use external lumbar arthrodesis and to restrict activities for a period of 6 weeks. The patients were then advised to engage in normal physical activity after confirmation of the status of screws. Postoperative imaging was done in the immediate postoperative phase and at followup examination (Fig. 1). 

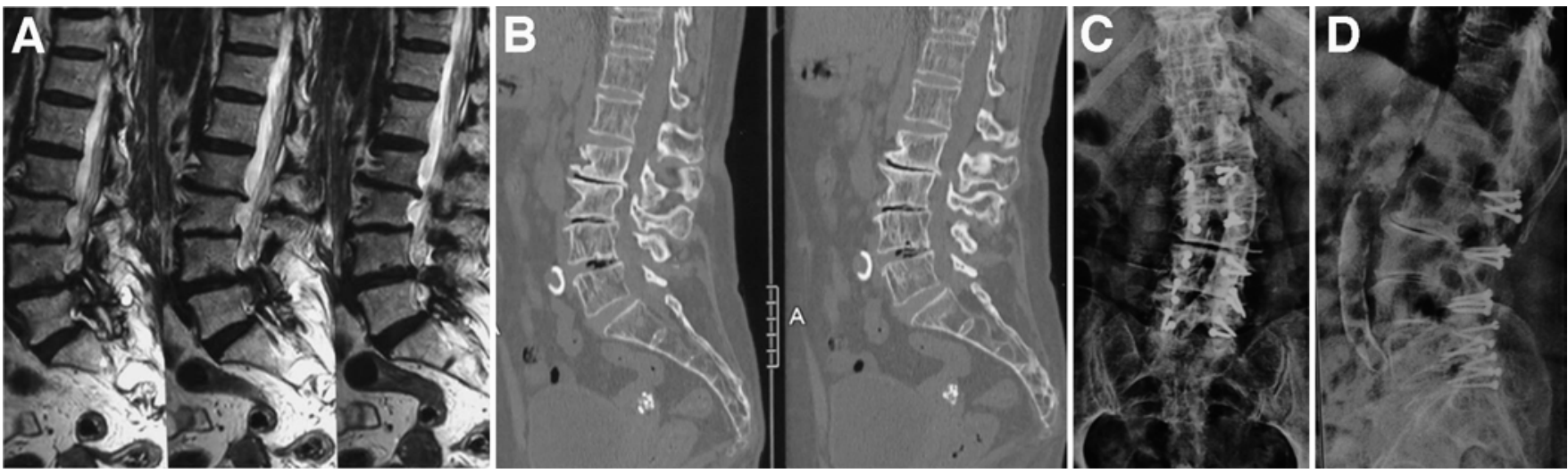

FIG. 1. A: T2-weighted MRI showing multilevel lumbar canal stenosis. B: CT scan showing evidence of spinal degeneration. C: Anteroposterior radiograph showing transarticular fixation performed using 2 screws at each articulation. D: Lateral radiograph showing the spinal fixation with screws.

\section{Results}

The follow-up duration ranged from 6 to 54 months (average 28 months). Independent observers who are not the authors of the present article did clinical assessment and radiological interpretations. All patients' symptoms improved in the immediate postoperative period to varying degrees. VAS and ODI scales were compared both before and after surgery. Apart from these measures, a patient satisfaction score developed in the local vernacular language assessed the status of clinical recovery. A summary of the questionnaire and the assessment outcome is shown in Table 3. During the period of follow-up there was no recurrence of symptoms in any case (Table 2).

Arthrodesis of the treated spinal segments was considered to be successful when at the minimum follow-up of 6 months the screw position remained stationary, bone fusion across the facets was observed, and dynamic imaging did not show relative movement of any vertebral component. With these minimum parameters, successful segmental arthrodesis was achieved in all cases. All patients were satisfied with the clinical outcome and are professionally active. In none of the cases was the operation repeated or any additional surgical maneuver done on the same level or at any other spinal level.

\section{Discussion}

Lumbar canal stenosis is a common clinical diagnosis, more commonly observed in patients in the elderly age group. In the United States, approximately $20 \%$ of the general population older than 60 years develops symptoms related to lumbar canal stenosis. ${ }^{3}$ Although similar figures are not available from less developed countries like India, the incidence appears to be more or less similar. Considering these large numbers, it is relevant that the subject is under constant evaluation, reevaluation, and scientific scrutiny.

Lumbar canal and root canal bone and ligamentous decompression has been the primary form of treatment for several decades. Lumbar traction and use of external lumbar orthoses or belts have enjoyed popularity as nonoperative forms of treatment for a long time. Our experience in the field suggests that the last word in the treatment format is yet to be said.

The pathogenesis of lumbar canal stenosis has been analyzed and reviewed for a long time. The generally accepted view is that the spinal degeneration is initiated by agerelated intervertebral disc dehydration or herniation. The accepted viewpoint is that following this primary event, there occurs loss of disc space height, bulge of the posterior anulus and posterior longitudinal ligament, overriding of the facets and infolding of the ligamentum flavum, and several similar events that eventually result in narrowing of the spinal canal dimension, or lumbar canal stenosis. Although the issue of instability has been under discussion in various forms, its role as a primary pathogenetic factor has never been universally accepted or analyzed. ${ }^{19}$ In general, in lumbar canal stenosis, the spine is considered to be stable. The symptoms of lumbar canal stenosis are related to posture and often increase on extension of the back, and are initiated on prolonged standing or walking. After a period of rest, the symptoms related to ca-

TABLE 3. Patient satisfaction score in 70 patients with lumbar canal stenosis

\begin{tabular}{lcccc}
\hline \multicolumn{1}{c}{ Parameter } & $\begin{array}{c}\text { Score 0 } \\
\text { (not satisfied) }\end{array}$ & $\begin{array}{c}\text { Score 1 } \\
\text { (minimally satisfied) }\end{array}$ & $\begin{array}{c}\text { Score 2 (satisfied) } \\
\text { (remarkably satisfied) }\end{array}$ \\
\hline Are you happy with the operation? & 0 & 0 & 7 & 63 \\
\hline Are you relieved of back and leg pain? & 0 & 0 & 10 & 60 \\
\hline Can you walk better? & 0 & 0 & 0 & 70 \\
\hline $\begin{array}{l}\text { Would you recommend the operation to some- } \\
\text { one else? }\end{array}$ & 0 & 0 & 5 & 65 \\
\hline
\end{tabular}


nal stenosis are reversed. Considering that the symptoms occur only after physical activity, this is suggestive that the spinal canal in not inherently stenosed but the physical activity initiates a phenomenon that leads to stenosis. It is apparent that weakness of the muscles of the back leads to their fatigue on exercise, and subsequent incompetence may lead to facetal overriding or telescoping. It is apparent that the phenomenon of lumbar canal stenosis is dynamic in nature and that local spinal instability plays a major role in the genesis of pain as a symptom and lumbar canal stenosis as a clinical entity. The human standing position, aging muscle, heavy body weight, and sedentary lifestyle may have a contributory effect on the pathogenesis of the entire spectrum of spondylosis or degeneration of the spine that eventually leads to lumbar canal stenosis.

In 2011, we identified for the first time in the literature the role of facetal distraction using the Goel facet distraction spacer as a form of treatment for both cervical and lumbar canal stenosis. ${ }^{6,714,15}$ The technique resulted in debuckling of the ligamentum flavum and posterior longitudinal ligament, and it increased the interspinal segmental distance that included intervertebral body distance and the spinal canal and neural foraminal girth. Essentially, the treatment resulted in an indirect neural decompression. No bone, soft-tissue, osteophyte, or disc resection was done. The technique aimed at arthrodesis of the spinal segment or segments without resorting to any kind of bone resection aimed at decompression. This technique was the first in the literature in which decompression by bone, disc, ligament, or osteophyte removal was not advocated as surgical treatment for the clinical entity of spinal canal stenosis. Other authors have recently presented their results of successful treatment by facet distraction techniques. ${ }^{16,18,22}$ Similar forms of treatment by distraction performed using spinous process and laminar distraction devices are currently gaining popularity.,2,17,20

As our understanding of spinal degeneration matured further, we realized that it was not neural compression or deformation that was the cause of symptoms in chronic or longstanding and progressive degenerative disease, but subtle instability-related microinjury to the neural structures that was the cause of neurological symptoms and deficits. ${ }^{9}$ We observed that radiological identification of vertical spinal instability is difficult or impossible due to the lateral location of the facets and their oblique profile. ${ }^{12}$ Direct observation of the status of facets and their stability was probably the only method to identify the evidence of instability. Our more than 30-year experience of manipulating the facets, initially of the craniovertebral junction and later of subaxial spine, has placed us in an advantageous position to identify the status of stability of the spinal segment. ${ }^{10,11,13}$ With clinical and radiological guidance, the instability of the lumbar spinal segments was diagnosed by direct physical observation and manual manipulation of bones. ${ }^{5}$ Transarticular fixation performed using 2 or 3 screws was identified to be safe, simple, and quick, and it is an effective technique of stabilization that works at the site of the fulcrum of spinal movements at the facet joint. Zero local movement that is provided by the technique results in immediate postoperative relief from symptoms and provides a reliable environment for bone arthrodesis.
Our remarkable clinical results obtained in our previously reported series involving both lumbar and cervical spinal degeneration and the $100 \%$ satisfactory outcome in the present experience are clearly suggestive of the effectiveness of the proposed surgical strategy. ${ }^{10,11,13}$ The symptomatic recovery was seen in the immediate postoperative period and was progressive. The observations suggest that decompression of neural tissue by procedures like laminectomy and foraminotomy is avoidable.

The drawback of our study is that a parallel cohort of patients in whom the surgery was done in the traditional manner was not available. Moreover, the number of patients treated was relatively small and the follow-up period is relatively short. Decompression of compressed or stenosed nerves forms the basic tenet of spine surgery. On the other hand, our technique suggests the futility of direct or indirect decompression as a mode of treatment. Considering the implications of our observation for the treatment of this common ailment, more studies by larger groups is mandatory before any definitive conclusions can be drawn. The concept is unique and the surgical treatment method is different than the traditional and widely accepted form of therapy, and will need to be reproduced by other investigators.

\section{Conclusions}

On the basis of our present and earlier experience, we conclude that vertical spinal instability and listhesis (i.e., telescoping or overriding of the facets) that exaggerates on physical activity has a defining role in the generation of symptoms of claudication pain and in the pathogenesis of lumbar canal stenosis. Only fixation at the site of the fulcrum of spinal movement is a rational and effective form of surgical treatment. Any kind of surgery that aims at decompression of neural structures is not necessary.

\section{References}

1. Alfieri A, Gazzeri R, Prell J, Scheller C, Rachinger J, Strauss $\mathrm{C}$, et al: Role of lumbar interspinous distraction on the neural elements. Neurosurg Rev 35:477-484, 2012

2. Bono CM, Vaccaro AR: Interspinous process devices in the lumbar spine. J Spinal Disord Tech 20:255-261, 2007

3. Buser Z, Ortega B, D’Oro A, Pannell W, Cohen JR, Wang J, et al: Spine degenerative conditions and their treatments: national trends in the United States of America. Global Spine J 8:57-67, 2018

4. Fairbank JCT, Pynsent PB: The Oswestry Disability Index. Spine (Phila Pa 1976) 25:2940-2952, 2000

5. Goel A: Beyond radiological imaging: direct observation and manual physical evaluation of spinal instability. J Craniovertebr Junction Spine 8:88-90, 2017

6. Goel A: Facet distraction-arthrodesis technique: can it revolutionize spinal stabilization methods? J Craniovertebr Junction Spine 2:1-2, 2011

7. Goel A: Facet distraction spacers for treatment of degenerative disease of the spine: rationale and an alternative hypothesis of spinal degeneration. J Craniovertebr Junction Spine 1:65-66, 2010

8. Goel A: Lumbar fusion for degenerative disease: a systematic review and meta-analysis. Neurosurgery 81:E64-E65, 2017 (Letter)

9. Goel A: Not neural deformation or compression but instabil- 
ity is the cause of symptoms in degenerative spinal disease. $\mathbf{J}$ Craniovertebr Junction Spine 5:141-142, 2014

10. Goel A: 'Only fixation' as rationale treatment for spinal canal stenosis. J Craniovertebr Junction Spine 2:55-56, 2011

11. Goel A: Only fixation for lumbar canal stenosis: report of an experience with seven cases. J Craniovertebr Junction Spine 5:15-19, 2014

12. Goel A: Vertical facetal instability: is it the point of genesis of spinal spondylotic disease? J Craniovertebr Junction Spine 6:47-48, 2015

13. Goel A, Goel AA, Satoskar SR, Mehta PH: Double insurance transfacetal screws for lumbar spinal stabilization. J Craniovertebr Junction Spine 5:85-87, 2014

14. Goel A, Shah A: Facetal distraction as treatment for singleand multilevel cervical spondylotic radiculopathy and myelopathy: a preliminary report. J Neurosurg Spine 14:689696, 2011

15. Goel A, Shah A, Jadhav M, Nama S: Distraction of facets with intraarticular spacers as treatment for lumbar canal stenosis: report on a preliminary experience with 21 cases. J Neurosurg Spine 19:672-677, 2013

16. Grasso G, Landi A: Preliminary experience with lumbar facet distraction and fixation as treatment for lumbar spinal stenosis. J Craniovertebr Junction Spine 8:193-198, 2017

17. Lo TP Jr, Salerno SS, Colohan AR: Interlaminar spacer: a review of its mechanism, application, and efficacy. World Neurosurg 74:617-626, 2010

18. Maulucci CM, Sansur CA, Singh V, Cholewczynski A, Shetye SS, McGilvray K, et al: Cortical bone facet spacers for cervical spine decompression: effects on intervertebral kinetics and foraminal area. J Neurosurg Spine 24:69-76, 2016

19. Resnick DK, Watters WC III, Mummaneni PV, Dailey AT, Choudhri TF, Eck JC, et al: Guideline update for the performance of fusion procedures for degenerative disease of the lumbar spine. Part 10: lumbar fusion for stenosis without spondylolisthesis. J Neurosurg Spine 21:62-66, 2014

20. Röder C, Baumgärtner B, Berlemann U, Aghayev E: Superior outcomes of decompression with an interlaminar dynamic device versus decompression alone in patients with lumbar spinal stenosis and back pain: a cross registry study. Eur Spine J 24:2228-2235, 2015

21. Roy-Camille R, Saillant G: [Surgery of the cervical spine. 2. Dislocation. Fracture of the articular processes.] Nouv Presse Med 1:2484-2485, 1972 (French)

22. Tan LA, Straus DC, Traynelis VC: Cervical interfacet spacers and maintenance of cervical lordosis. J Neurosurg Spine 22:466-469, 2015

\section{Disclosures}

The authors report no conflict of interest concerning the materials or methods used in this study or the findings specified in this paper.

\section{Author Contributions}

Conception and design: Goel, Shah. Acquisition of data: all authors. Analysis and interpretation of data: all authors. Drafting the article: all authors. Critically revising the article: Goel, Shah. Reviewed submitted version of manuscript: all authors. Approved the final version of the manuscript on behalf of all authors: Goel. Administrative/technical/material support: Goel.

\section{Correspondence}

Atul Goel: K.E.M. Hospital and Seth G.S. Medical College, Parel, Mumbai, India. atulgoel62@hotmail.com. 